\title{
Safety and Mechanism of Action of Licensed Vaccine Adjuvants
}

\author{
*Dirga Sakti Rambe ${ }^{1}$, Giuseppe Del Giudice ${ }^{2}$, Stefania Rossi ${ }^{3}$ and Melvin Sanicas ${ }^{1}$ \\ ${ }^{1}$ Faculty of Medicine and Surgery, University of Siena, Siena, Italy \\ ${ }^{2}$ Novartis Vaccines, Via Fiorentina 1, 53100 Siena, Italy \\ ${ }^{3}$ Department of Molecular \& Developmental Medicine, University of Siena, Siena, Italy
}

\begin{abstract}
Vaccines are some of the most effective tools for the prevention of infectious diseases. Adjuvants are included in vaccines for a variety of reasons: to increase the breadth of response, to lower antigen dose, to overcome limited immune response in some populations, or to enable complex combination vaccines. This study aims to review the safety of licensed vaccine adjuvants and describe their mechanism of action. Potential publications for inclusion were identified through a direct search of PubMed/Medline database. Results of online literature searches were supplemented by relevant papers cited in published studies along with the authors' knowledge of published studies. To date, there are 5 licensed vaccine adjuvants in US and Europe: Aluminum salts (EU, US), MF59 (EU), AS03 (EU), AS04 (EU, US), and virosomes (EU). AS03 is not available as an adjuvant in other vaccines but included within the US government's National Stockpile. All vaccines that contain these adjuvants have been proven safe in clinical trials and post-marketing studies, with the exception of the AS03, for which the rare events of narcolepsy have been reported in some countries. Every adjuvant has a complex and often multifactorial immunological mechanism, usually poorly understood in vivo. The safety profile of an adjuvant, including the actual and hypothetical risks, is a critical component that can speed up or impede adjuvant development. The increasing understanding in adjuvant sciences is fundamental to the further development of new adjuvants.
\end{abstract}

Key Words: Vaccine adjuvants, alum, MF59, AS03, ASO4, virosomes.

\section{INTRODUCTION}

Vaccines are some of the most effective tools for the prevention of infectious diseases (Halsey, 2003). Despite the fact that currently licensed vaccines have been proven to be safe, safety issues have emerged that have resulted in some members of the public having a poor perception of vaccines. As vaccine usage increases and the incidence of vaccine-preventable diseases is reduced, vaccinerelated adverse events become more frequent and prominent (Offit et al., 2008; O'Hagan and Rappuoli, 2004; Mc Phillips and Marcuse, 2001). The majority of vaccines currently in development consist of highly purified antigens or recombinant proteins, representing subunits of pathogens. The common strategy for the development of new-generation vaccines is to add well characterized adjuvants that only stimulates the component of the immune response essential for protection, and do not trigger a more generalized activation of the immune response (O'Hagan, 2001). In spite of obvious benefits, decades of research and hundreds of pre-clinical candidates, and proven safety and efficacy, only a handful of adjuvants are currently approved for prophylactic vaccination of humans (Schijns and Lavelle, 2011).

Adjuvants are included in vaccines for a variety of reasons. They may function to amplify the immune response, resulting in lower antigen doses that are required for a robust response to vaccination while increasing the breadth of response. Additionally, adjuvants allow for the formulation of complex combination vaccines thereby overcoming antigenic competition. Furthermore, adjuvants are extremely important in
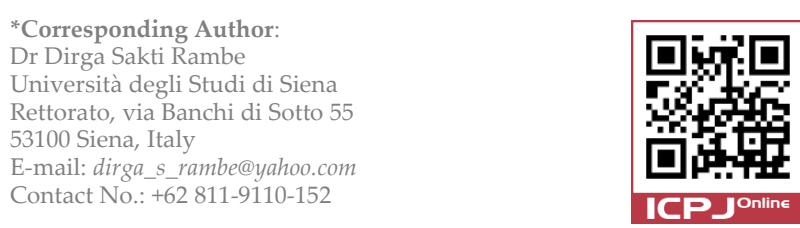

enhancing the limited immune response in some populations, such as the elderly, young children, chronic diseases and immunocompromised. They also function to increase effector $\mathrm{T}$ cell response and antibody titers, induce protective responses more rapidly, extend the duration of the response by enhancing memory $\mathrm{B}$ and $\mathrm{T}$ cell responses and facilitate increased vaccine stability (Schijns and Lavelle, 2011; O'Hagan and Gregorio, 2009).

The development and eventual introduction of new adjuvant for vaccines is a challenging and daunting task for not only the vaccine manufacturers but also the regulatory authorities (Sesardic and Dobbelaer, 2004). Adjuvants are not licensed alone without being incorporated into a vaccine because it is a part of the vaccine (Verdier, 2002). Proper and thorough preclinical and toxicology studies need to be developed and designed to appropriately determine the safety profile of the adjuvant and the safety profile of the combination of the antigen and the adjuvant (Sesardic et al., 2007). Safety and a lack of universality appear to be the major hurdles for the acceptance of new adjuvant. The European Medicines Agency (EMA) published a guidance that emphasizes a number of additional points: quality of manufacture of the adjuvant alone and in combination with vaccine antigens, nonclinical proof of concept and toxicity studies, and clinical development that assesses the adjuvant effect and dose required (EMA, 2005). Since each combination of one or more antigens with an adjuvant has its unique safety and efficacy profile, they are licensed and regulated as individual vaccine products in combination Kenney and Cross, 2010). Currently, there are only 5 licensed vaccine adjuvants for human use: Alum, MF59, Virosomes, AS03 and AS04. Safety has always been the main obstacle to the development of new vaccine adjuvants (O'Hagan and Gregorio, 2009; Vogel and Hem, 2008; Glenn and O'Hagan, 2007; Brennan and Dougan, 2005). Thus, this manuscript aims to review the safety of licensed vaccine 
adjuvants and describe the proposed mechanism of action of those adjuvants.

\section{METHODS}

Potential publications for inclusion were identified through a direct search of PubMed/Medline database (http://www.ncbi.nlm.nih.gov/pubmed/). Other sources of information used included textbooks and internet searches (www). The following search terms were used: "adjuvant(s)", "vaccine adjuvant", "adjuvanted vaccines", "safety of vaccine", "safety of adjuvant", "licensed vaccine adjuvants", "alum adjuvant". All articles were reviewed to select relevant publications. Results of online literature searches were complemented by relevant papers cited in published studies along with the authors' knowledge of published studies.

\section{RESULTS}

There are several new adjuvants in preclinical and clinical development. Some new adjuvants have recently been licensed for human use in the EU. Alum has represented the only adjuvant licensed in US until 2010 when the HPV vaccine containing AS04 adjuvant was licensed (table 1). This review will only focus on the licensed vaccine adjuvants.

\section{Aluminum salts}

Mechanism of action

Three probable mechanisms have often been cited to explain how aluminum-containing adjuvants increase antibody production; the inflammation mechanism; the depot mechanism, and the promotion of uptake of antigens by APCs (Gupta et al., 1995). Recent work proposed that particulate adjuvant is not simply antigen delivery systems but can also act as immunopotentiators (Edelman, 2002). Alum has been shown to activate human monocytes and macrophages in vitro (Rimaniol et al., 2004; Ulanova et al. 2001; Seubert et al., 2008) and synergize with TLR-dependent adjuvants resulting in the secretion of IL-1 $\beta$ by human peripheral blood mononuclear cells (PBMCs) as a result of the activation of the inflammasome complex (Li et al., 2007). Injection of Alum induced the enrollment of inflammatory monocytes that were able to move into lymph nodes, and the formation of uric acid, which stimulates the immune system through the NLRP3 inflammasome complex (Kool et al., 2008). As already described, NLRP3 has been implicated in Alum adjuvanticity (Eisenbarth et al., 2008). However, the direct mechanism of action has yet to be determined.

Alum does not effectively induce mucosal $\operatorname{IgA}$ antibody responses. In addition, Aluminum salts primarily stimulate a Th2 response, which results to the induction of IgE antibody production, and possibly associated with allergic reactions in some subjects (Gupta, 1998; Relyveld et al., 1998). The dose of aluminum adjuvant is an essential consideration. It is important to understand that there may be an optimal level of aluminum for a given vaccine antigen, with immune responses decreasing at increased levels of aluminum. Nevertheless, aluminum has been found to remain at the site of injection for a long period (Gupta, 1998). Small particles of aluminum salts can be internalized by dendritic cells (Morefield et al., 2005) and are known to be removed from the body over time (Hem, 2002). The acceptable dose of aluminum in adjuvants ranges up to $1.25 \mathrm{mg}$ both by US and by WHO regulations, but currently licensed US vaccines have a range of only $0.125-0.85 \mathrm{mg}$ (Baylor et al., 2002).

\section{Safety}

Alum has been the usual first choice for many vaccines due to its long history of use and known safety profile (Alving, 2009). Alum-adsorbed vaccines induce local reactions (for example redness, pain, and hardening of the injection site) in a significant number of recipients, but these adverse reactions are frequently light to moderate and of short duration. Systemic reactions can infrequently happen, including malaise, fever and aches $\left(\mathrm{O}^{\prime}\right.$ Hagan and Rappuoli, 2004). Focal histologic lesions linked to alumcontaining vaccines, which is known as Macrophagic Myofasciitis (MMF), were first reported in France in 1998. Five years later, more than 200 definite cases have been identified, and isolated cases have been documented in other countries (Gherardi, 2003). A retrospective analysis of 18 cases seen in five myopathology centers was done between May 1993 and December 1997. Polymyositis (inflammatory muscular disease) and polymyalgia rheumatica (sometimes referred to as PMR) were the leading presumptive diagnoses. Twelve patients reported myalgia, nine reported arthralgia, six reported muscle weakness, five reported pronounced asthenia, and four reported fever. Abnormal laboratory findings were infrequently observed which included increased creatine kinase, increased erythrocyte sedimentation rate and myopathic electromyography (Gherardi et al., 1998).

Muscle biopsy findings included focal infiltration of epimysium, perimysium and perifascicular endomysium

Table 1: Adjuvants for Human Use (O'Hagan and Gregorio, 2009; Vogel and Hem, 2008; Glenn and O'Hagan, 2007).

\begin{tabular}{lllll}
\hline Name & Company & Class & Indications \\
\hline Alum & Various & Mineral salt & Various & Stage \\
MF-59 & Novartis & O/W emulsion & Influenza (Fluad)/pandemic flu (Focetria) & Licensed (EU) \\
Virosomes & Crucell & Lipid vesicles & HAV, Flu & Licensed (EU) \\
Montanide & Various & W/O emulsion & Dalaria, Cancer & Phase III \\
PLG & Novartis & Polymeric microparticle & Flu vacine (HIV) \\
Flagellin & Vaxinnate & Flagellin linked to antigen & Various \\
QS21 & Antigenics & Saponin & Malaria, TB & Phase I \\
AS01 & GSK & MPL+liposomes+QS21 & Paria \\
AS02 & GSK & MPL+O/W emulsion+QS21 & Pandemic flu (Pandemrix) \\
AS03 & GSK & O/W emulsion+ $\alpha$ tocopherol & HBV (Fendrix), HPV (Cervarix) \\
AS04 & GSK & MPL+alum & Various \\
Iscom & CSL, Isconova & Saponins+cholesterol +phospolipids & TB \\
IC31 & Intercell & Peptide+oligonucleotides & Phase II \\
CpG 7909 & Coley/Pfizer-Novartis & Oligonucleotides+alum, oligonucleotides+MF59 & HBV, Malaria, HCV \\
ISS & Dynavax & Oligonucleotide alum & HBV & Licensed (EU, US) \\
AF03 & Sanofi Pasteur & O/W emulsion & Pandemic flu (Humenza) I \\
\hline
\end{tabular}


by sheets of large basophilic cells of the monocyte and macrophage lineage $\left.\left(\mathrm{CD}^{\circ} 8^{+}, \mathrm{CD}_{1} \mathrm{a}^{-}, \mathrm{S100}\right)^{-}\right)$. These cell infiltrates express major histocompatibility complex (MHC) class 1 and MHC class 2 antigens, with a finely granular periodic acid-Shiff (PAS)+ content appearing as small osmiophilic spiculated structures on electron microscopy. Additional lymphocytic infiltrates intermixed with macrophages and formed micro vascular cuffs of CD8 T cells or lymphoid follicles with an observed lack of significant muscle fiber injury. Microorganisms were not detected using typical staining (Ziehl-Neelsen, auramine, Gram) or via electron microscopy. The myopathologic pattern was different from idiopathic and sarcoid-like inflammatory myopathies and from fasciitis-panniculitis syndromes (Gherardi \& Authier, 2003; Naschitz et al., 1996).

Patients had normal results on both renal function tests and aluminum plasma levels, which lead the investigators to consider the likelihood of a focal accumulation of aluminum unrelated to passive deposition from the blood. Macrophage infiltrates were not observed elsewhere than in muscle in adult patients (Gherardi et al., 1998), and in fact the MMF lesion was detected completely in the deltoid muscle (Gherardi et al., 2001). Because aluminium salts are used as an adjuvant in several vaccines administered intramuscularly into deltoid and quadriceps muscles, it has been postulated that MMF may represent a rare and unusual reaction to intramuscular injections of aluminium-containing vaccines (Gherardi and Authier, 2003).

The Vaccine Safety Advisory Committee (VSAC) of the World Health Organization (WHO) reviewed MMF in 1999. The VSAC concluded that there was no basis for recommending a change in vaccination practices involving vaccine selection, schedule, delivery practices, or information involving aluminum-containing vaccines. The VSAC also recommended further research to assess the clinical, epidemiological and basic science aspects of MMF (WHO, 1999). The US Food and Drug Administration (US FDA) also validated the safety of aluminum salts in vaccines (Baylor et al., 2002).

Studies have demonstrated that at all time points after vaccination, the calculated body burden of aluminum remains less than the minimal risk level (Keith, 2002). Thorough evaluation of hundreds of thousands of doses of whole-cell and acellular pertussis vaccines and hepatitis B vaccines (most of which contained aluminum adjuvants) derived from large population trials and cohort studies has shown no evidence of serious or longterm effects (Jefferson et al., 2003; Demicheli et al., 2003). A meta-analysis of the available safety data on alum from 35 reports of studies found no evidence of serious or longterm adverse effects (Jefferson et al., 2004).

\section{MF 59}

Mechanism of action

MF59 was the $1^{\text {st }}$ adjuvant to be approved for human use after aluminum salts. Despite limitations and numerous endeavors over the years to identify alternative adjuvants, aluminum salts continued to be the only vaccine adjuvant acceptable for human use until the late 1990s. The first alternative adjuvant to gain acceptance since aluminum salts was MF59 emulsion, which gained approval for human use first in Italy in 1997, then in 23 countries (including 12 in EU) for use as a part of the influenza vaccine for elderly subjects. MF59 was discovered, developed and is currently produced by Novartis Vaccines (now part of GSK vaccines). The long period between the introduction of aluminum salts and that of
MF59 was mainly due to the safety profile required of adjuvants to gain approval for use in humans. Unlike several earlier candidates, MF59 met all the required criteria for safety (Podda et al., 2005; Sahly, 2010; Pellegrini et al., 2009). MF59 was originally developed as a vehicle for a muramyl peptide adjuvant, MTP-PE, but was found to possess distinct adjuvant properties. The current version of the MF59 emulsion is a second-generation formulation with the addition of citrate for better stability (Podda et al., 2005).

MF59 has been demonstrated to be an effective adjuvant in a varied range of species in combination with an extensive range of vaccine antigens, including recombinant proteins, isolated viral membrane antigens, bacterial toxoids, protein polysaccharide conjugates, peptides, and virus-like particles. MF59 is particularly effective at inducing high levels of antibodies, including functional titers (neutralizing, bactericidal and opsonophagocytic titers) and is commonly more potent than aluminum salt adjuvants (figure 1). The level of immunogenecity achieved over aluminum salts is adaptable and is determined by the antigen and species under evaluation (Podda et al., 2005; Singh et al., 2006). In spite of known efficacy, the mechanism of action of MF59 is not completely understood. Initial reports attributed the mechanism of action to a depot effect; providing the antigen in an oil-in-water emulsion that results in a slow release of the antigen (Herbert, 1966). Nonetheless, the depot effect of the MF59 adjuvant was later disputed after a study showed that soluble gD2 antigen from herpes simplex virus (HSV) and MF59 injected intramuscularly in mice had varying clearance kinetics and the presence of MF59 did not modify the clearance kinetics of the antigen (Dupuis et al., 2000). Using a comparable model, Dupuis et al. found out that MF59 was internalized by dendritic cells (DCs) and facilitated the internalization of the gD2 antigen, therefore developing the possibility that a direct interaction with and activation of dendritic cells are more probable explanations of the adjuvant effect (Dupuis et al., 1998).

\section{Safety}

Literature on the safety of MF59 in humans can be divided into two categories: data from clinical trials and data from post-marketing safety surveillance. Clinical trials using numerous MF59-adjuvanted vaccines have been completed in different age groups (elderly, younger adults, adolescents, newborn infants), and demonstrate increased immunogenicity of co-administered antigens with a high level of safety and tolerability (Podda et al., 2005; O'Hagan et al., 2011). For the most part, clinical experience and safety data of MF59 safety have been collected in conjunction with influenza vaccines that have followed over 14,000 individuals vaccinated in more than 30 clinical studies (Podda et al., 2005; Frey et al., 2003; Banzhoff et al., 2003; Gasparini et al., 2001; Podda, 2001; De Donato, et al., 1999; Minutello et al., 1999; Martin, 1997). For instance, Fluad ${ }^{\circledR}$ had been studied in 28 single- or double-blind, randomized and controlled studies, 13 of which with a 4- to 6-month follow-up and 12 studies with a 4-week follow-up before it was granted approval in May 1997. Twenty-four of 30 studies included elderly subjects ( $\geq 65$ years). Fluad ${ }^{\circledR}$ was tested for equivalence of antigenic content against the inactivated subunit comparator vaccine Agrippal ${ }^{\circledR}$ (same antigenic content but without MF59), in twenty, against Fluogen $\AA /$ Fluvirin ${ }^{\circledR}$ in one study, against Fluzone ${ }^{\circledR}$ in two studies, against Influvac ${ }^{\circledR}$ in three studies, and against Flushield ${ }^{\circledR}$ in two studies (Schultze et al., 2008). 


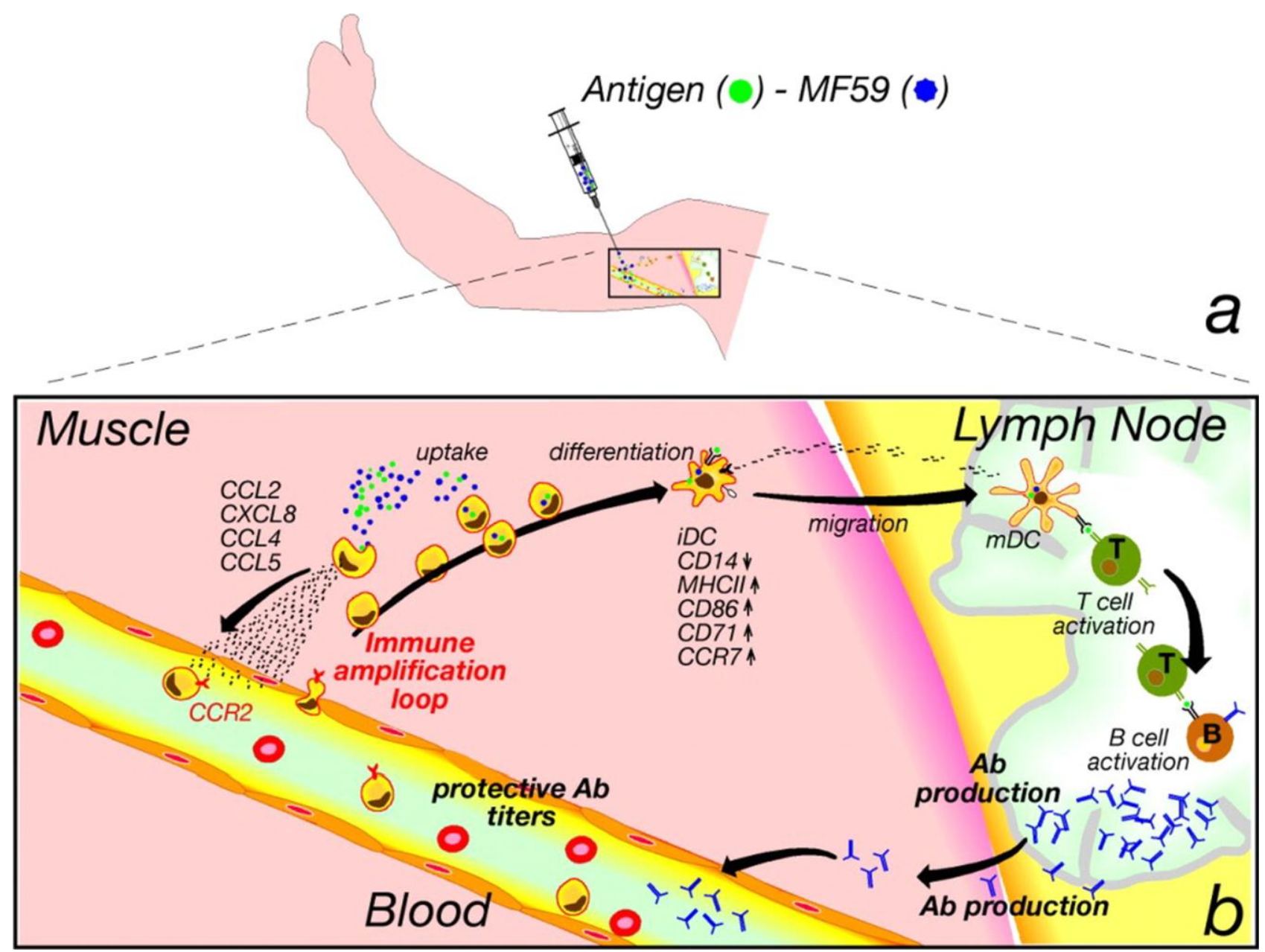

Figure 1: Mechanism of Action of MF59 (Seubert et al., 2008).

Moreover, MF59 has been studied in clinical trials with herpes simplex virus (HSV), human immunodeficiency virus (HIV), cytomegalovirus (CMV), hepatitis B virus (HBV), hepatitis $\mathrm{C}$ virus (HCV), E. coli, parvovirus, and human papilloma virus (HPV) vaccine candidates. MF59 has also been tested in various formulations, including single-container presentation (HSV vaccine, influenza vaccine), dual container without buffer in the MF59 portion (influenza vaccine), and dual container with citrate buffer in the MF59 portion (HBV vaccine, influenza vaccine), like the current vaccine formulation (Schultze et al., 2008).

There are two integrated analyses of safety data from MF59-adjuvanted influenza vaccine clinical trials. A meta-analysis published in 2001 assessed the safety data from 20 clinical trials that were performed as part of the Fluad ${ }^{\circledR}$ registration package submitted for evaluation to the European Medicines Agency (EMA) (Podda, 2001). Five of 20 trials evaluated the safety of the vaccine given annually in the second influenza season, while 2 of the trials evaluated the vaccine in the third ensuing influenza seasons. All study subjects were elderly ( $\geq 65$ years of age) and received 1 dose of MF59-adjuvanted seasonal influenza vaccine or non-adjuvanted seasonal influenza vaccine (Podda, 2001).

In 2009, a more recent analysis encompassing the aforementioned 20 trials and an additional 44 other trials were published (Pellegrini et al., 2009). The trials were heterogeneously designed in terms of age group (infant to elderly), study design (controlled and uncontrolled), duration of observation ( 3 weeks to $>12$ months) and the antigen used (pandemic or interpandemic influenza). The study supported the good safety profile of seasonal and pandemic influenza vaccines with MF59 and demonstrated benefit over influenza vaccines without MF59. An observational cohort study with a 3-month follow-up of neonates was done in 4,508 pregnant women (2295 vaccinated versus 2213 unvaccinated) to assess the safety of a MF-59 adjuvanted A/H1N1 vaccine (Focetria $\left.{ }^{\circledR}\right)$. No maternal deaths or abortions were recorded among the vaccinated women. In addition, there were no differences between the vaccinated and unvaccinated cohorts observed for gestational diabetes, pre-eclampsia, stillbirth, low birth weight, neonatal deaths or congenital malformation after vaccination in all trimesters. The risk of premature birth was significantly lower among the women who got Focetria ${ }^{\circledR}$ (adjusted proportional hazard: 0.69; 95\% CI: 0.51-0.92). (Heikkinen et al., 2012). In 2009, a study assessed the safety and immunogenicity following a second year seasonal vaccination with Fluad ${ }^{\circledR}$ in children. With 89 subjects enrolled, it was demonstrated that the use of MF59-adjuvanted influenza vaccine was safe and highly immunogenic in young children (Vesikari et al., 2009).

The positive safety profile of MF59-adjuvanted vaccines, as shown in clinical trials, are also supported by post-marketing pharmacovigilance. A review of the postmarketing surveillance data of Fluad ${ }^{\circledR}$ or Fluad®-like 
vaccines from September 1997 to August 2006 reported 1,400 single adverse events during a 9-year period whereby millions of doses of adjuvanted vaccines were administered (Schultze et al., 2008). To ensure coherence and consistency of reported events, all were classified according to MedDRA. There were 13 cases of deaths reported, largely due to cardiovascular causes in older patients 68-91 years of age. None of these cases was attributed to the vaccine. Thirty-nine allergic reactions were reported, 7 were serious and none was fatal. There were 8 cases of encephalitis/myelitis reported, 2 of which were considered related to the vaccine. Nine cases of Guillain-Barré syndrome were recorded, reflecting an incidence of 0.03 cases per 100,000 recipients. This is lower than the annual incidence of Guillain-Barré syndrome in the general population (estimated to be at $0.6-4$ cases per 100,000 persons). Three cases of Parsonage-Turner syndrome (acute brachial neuropathy and acute brachial radiculitis), 4 cases of thrombocytopenia, 1 case of leukocytosis, 3 cases of vasculitis and 1 case of purpura/microhematuria were reported (Schultze et al., 2008). Banzhoff et al. reported spontaneous adverse drug reactions (ADR) from an estimated 12 million administered doses of the pandemic MF59-adjuvanted H1N1v vaccine (Focetria $\left.{ }^{\circledR}\right)$ from the mass vaccination programs in Europe. A total of 5,315 pandemic vaccine ADR reports were received, of which $19.9 \%$ were serious. An rise in the reporting rate was observed after the use H1N1 pandemic vaccines (44.3 cases/100,000 doses). Rates of adverse events of special interest, for instance, Guillain-Barre syndrome, anaphylaxis, and convulsion, were similar between the pandemic and the seasonal vaccines. Thirtysix deaths were recorded after use of the pandemic vaccine, but none of them showed evidence for a causal relationship to the vaccine (Banzhoff et al., 2011). Additionally, the MF59-adjuvanted pandemic vaccine did not demonstrate any association with narcolepsy, unlike the pandemic vaccine from GSK with the AS03 adjuvant (Tsai et al., 2011).

\section{AS03}

Mechanism of action

GlaxoSmithKline Biologicals (GSK; Rixensart, Belgium) has developed novel adjuvant combinations, called Adjuvant Systems. One such adjuvant system is AS03, an oil-in-water emulsion developed as an alternative to the water-in-oil emulsions, known to be potent immunostimulants but have been known to be too reactive for human use. The presence of $\alpha$-tocopherol differentiates AS03 from other oil-in-water emulsion-based adjuvants (Garcon et al., 2012). $\alpha$-tocopherol is 1 of the eight isoforms of vitamin $\mathrm{E}$ and the most widely distributed in nature (Brigelius-Flohe and Traber, 1999). It is also the form that better absorbed in the human body and found in various tissues including muscle fibers, adipose tissue, adrenal glands, pituitary glands, and the pancreas (Burton et al., 1998). AS03 needs co-localization with antigen at the injection site. It stimulates short-lived expression of the transcription factor $\mathrm{NF}-\kappa \mathrm{B}$, cytokine and chemokine responses and an amplified recruitment of innate immune cells to the site of injection. Monocytes are the major cell type that is activated to convert to antigen-presenting cells (APCs) and migrate to draining lymph nodes once loaded with antigen. The APCs then trigger naive CD4+ T cells, which interact and stimulate antigen-specific $\mathrm{B}$ cells (i.e. memory B cells and antibody-secreting plasma cells) (Garcon et al., 2012).
Safety

The safety of the AS03-adjuvanted H5N1 vaccine has been evaluated in over 10,000 adults across different populations. In Phase III studies involving 5,071 (Rumke et al., 2008) and 4,561 subjects (Langley et al., 2011), solicited local and general symptoms were more common in the AS03-adjuvanted vaccine groups than in the control groups (seasonal influenza vaccine and PBS, respectively), but symptoms were not serious and low grade in general. In adults (aged 18-60 years) from the first study (Hem et al., 2006), $88 \%$ of subjects who received the first dose of the AS03-adjuvanted vaccine reported pain versus $64 \%$ of those who received the non-adjuvanted vaccine; $35-41 \%$ of subjects who received the first dose of AS03-adjuvanted vaccine reported fatigue, headache and myalgia versus $21-25 \%$ of those who received the non-adjuvanted vaccine. The occurrence and seriousness of recorded adverse events were in general lower with the second dose (Rumke et al., 2008) and in older versus younger adults (Garcon et al., 2012; Rumke et al., 2008; Langley et al., 2011). Over 90 million doses of AS03-adjuvanted H1N1 vaccine were administered globally in $>47$ countries during the 2009-2010 H1N1 pandemic including some 9.6 million children and 1.5 million pregnant women. Active safety surveillance performed by national regulatory authorities during the pandemic season showed a clinically acceptable benefit-risk profile for the AS03adjuvanted H1N1 vaccines (Garcon et al., 2012).

Cases of narcolepsy, especially in children and adolescents, following widespread use of vaccines against influenza (H1N1) 2009 have been reported since August 2010. Among the 30 countries that used the Pandemrix/Arepanrix vaccine in the autumn/winter seasons of 2009-2010, only Finland, Sweden and Iceland reported narcolepsy incidence higher compared to the previous years. Pandemrix (GSK) was the sole pandemic influenza vaccine used in these countries (WHO, 2011). A retrospective review of all new narcolepsy cases recorded during 2006-2010 was conducted. In the period 2009-2010, the risk of narcolepsy in people aged 4-19 years old who received the pandemic influenza vaccine was $9 \mathrm{X}$ higher compared to those unvaccinated. The results suggest a risk of about 1 case of narcolepsy per 12,000 vaccinated in this specific age group. However, in the younger or older age groups, there was no increased risk (WHO, 2011; National Institute for Health and Welfare of Finland, 2011).

A retrospective cohort study in Finland demonstrated an abrupt increase in the incidence of childhood narcolepsy associated with AS03-adjuvanted AH1N1 vaccine (incidence of narcolepsy was 9.0/100,000 in the vaccinated versus $0.7 / 100,000$ person-years in the unvaccinated children and adolescents). The result translates to a rate ratio of 12.7 (95\% CI 6.1-30.8). In vaccinated 4 to 19 -year-olds, the vaccine-attributable risk of developing narcolepsy was 1:16,000 (95\% CI: 13,000$1: 21,000)$. This observation was supported by studies from Sweden. Conversely, both Canada and the United Kingdom did not report any increase in the frequency of narcolepsy after administration of Pandemrix even though genetic susceptibility to narcolepsy is as common in these countries as in the Nordics. This suggests a multifactorial nature of narcolepsy (Nohynek et al., 2012).

The Swedish Medical Products Agency issued a preliminary report on 28 March 2011 following an investigation on pandemic influenza vaccination from regional vaccination registries of 4 Swedish counties. The risk of narcolepsy was compared in vaccinated and unvaccinated individuals from October 2009 to December 
2010. The Agency reported the relative risk (RR) of narcolepsy was $4 \mathrm{x}$ higher in vaccinated children and adolescents (born from 1990) compared to unvaccinated children and adolescents. The RR translates into an absolute risk of about 3 cases of narcolepsy in 100,000 vaccinated adolescents/children. The incidence rates for narcolepsy in adults, whether vaccinated or unvaccinated, were similar to historical national registry-based rates during the years before the pandemic period (about 1/100,000) (Swedish Medical Products Agency, 2011). The European Medicines Agency's Committee for Medicinal Products for Human Use (CHMP) reviewed all available data, including new findings from Sweden and France. Similar to earlier results of the Finnish epidemiological study, the CHMP concluded that the new evidence, although having limitations in the methodology of the data, supported the signal in children and adolescents (WHO, 2011). Figure 2 shows the hypothetical model of autoimmunity in narcolepsy. Further studies are necessary to determine whether the association between adjuvanted pandemic vaccinations and narcolepsy can be demonstrated in other populations. Further research on the underlying immunological mechanism is also warranted.

\section{ASO4}

Mechanism of action

ASO4 is a combination of $50 \mu \mathrm{g}$ of the immunostimulator MPL (3-O-desacyl-4'-monophosphoryl lipid A) and 500 $\mu \mathrm{g}$ of aluminum salt. MPL is a detoxified form of the lipopolysaccharide extracted from the Gram-negative bacterium Salmonella, Minnesota strain R595. MPL includes an immune stimulatory activity similar in quality to lipopolysaccharide, albeit lower in magnitude. This was discovered to be due to the ability of MPL to act as a Tolllike receptor 4 (TLR4) agonist (Garcon, 2010; Qureshi et al., 1982; Casella and Mitchell, 2008; Didierlaurent et al., 2009). Two AS04-adjuvanted vaccines are licensed for human use: (1) the human papillomavirus 16/18 (HPV16/18) vaccine, Cervarix ${ }^{\circledR}$ (GlaxoSmithKline) and (2) FENDrix ${ }^{\circledR}$ (GlaxoSmithKline), a hepatitis B virus (HBV) vaccine for patients undergoing dialysis (Descamps et al., 2009). At present, the AS04-adjuvanted HPV-16/18 vaccine has been approved in over 110 countries while the AS04-adjuvanted HBV vaccine has been approved in over
30 countries including the 27 countries of the European Union (Beran, 2008).

AS04 stimulates localized and transient transcriptional activity of the transcription factor NF-kB, a key regulator of the innate response (Vallabhapurapu and Karin, 2009). AS04 stimulates transient production of cytokines at the site of injection. By 24 hours (Didierlaurent et al., 2009), AS04 directly triggers dendritic cells and monocytes to take up antigen and move towards the draining lymph nodes. The activated antigen-presenting cells (APCs) function to present antigen to and activate T cells. The fast and transitory stimulation initiated by AS04 allows the APCs to process and present antigens while the vaccine antigen concentration is elevated - this results in a more robust immune response (Garcon, 2010).

\section{Safety}

Pooled analysis of the safety of the HPV-16/18 AS04adjuvanted cervical cancer vaccine was concluded in a cohort of nearly 30,000 girls and women aged $\geq 10$ years, who received at least 1 dose of the HPV-16/18 vaccine and 13,811 who received 1 of 3 controls $[\mathrm{Al}(\mathrm{OH}) 3$ or hepatitis A vaccine]. Serious adverse events (SAEs), pregnancies, medically significant conditions (MSCs) and new onset of chronic diseases (NOCDs), including new onset of autoimmune diseases (NOADs), were monitored. Data were analyzed by vaccine group according to age (10-14, $15-25$ and $>25$ years) and reporting period (months $0-7$, months 7-12 and >month 12). Although rates of solicited local and general symptoms were higher in the HPV-16/18 vaccine group, there were no clinically relevant differences seen between the HPV-16/18 vaccine and pooled control groups in rates of SAEs $(2.8 \%$ versus $3.1 \%)$, MSCs (19.4\% versus $21.4 \%)$, NOCDs $(1.7 \%$ in both groups) or NOADs $(0.4 \%$ versus $0.3 \%)$, and no differences in pregnancy outcomes or rates of withdrawals due to AEs or SAEs were observed between the HPV-16/18 vaccine group and the control group. Results from the analysis of this large database confirm the favorable safety profile of the HPV-16/18 AS04-adjuvanted cervical cancer vaccine (Descamps et al., 2009).

When comparing the AS04-adjuvanted HPV 16/18 vaccine with the quadrivalent HPV vaccine from Merck (Gardasil $\left.{ }^{\circledR}\right)$, which is adjuvanted with aluminium

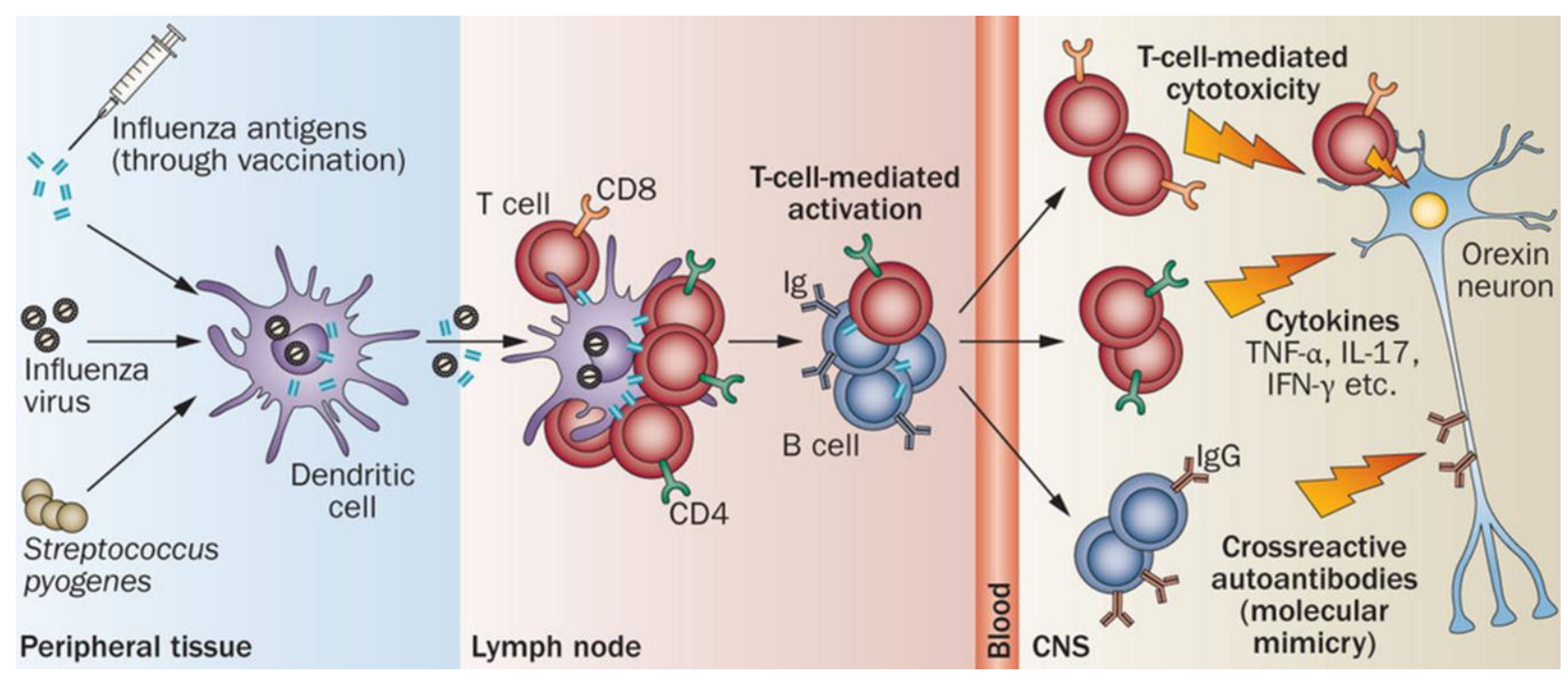

Figure 2: Hypothetical model of autoimmunity in narcolepsy (Julkunen and Partinen, 2014). 
hydroxide, the proportion of women reporting at least 1 solicited local or general adverse event within 7 days of any dose was $95 \%$ in the bivalent HPV vaccine group and $85 \%$ in the quadrivalent HPV vaccine group. The most common solicited local symptom in both groups was injection-site pain (93\% vs $72 \%$ ), and this was of grade 3 severity in $17 \%$ for the bivalent vaccine vs $3 \%$ for the quadrivalent vaccine. The local reaction associated with the AS04-adjuvanted HPV 16/18 vaccine is most probably related to the use AS04. The incidence of fatigue and myalgia was $50 \%$ and $28 \%$ with the bivalent HPV vaccine compared with $40 \%$ and $20 \%$ with the quadrivalent HPV vaccine. Adverse events were reported more frequently after the first dose than after subsequent doses in both vaccines. Rates of medically significant conditions were $30 \%$ and $27 \%$, respectively. SAEs were reported in 6 versus 7 women, respectively, and new-onset chronic disease in 14 and 13 women (McKeage and Romanowski, 2011; Einstein et al., 2009).

The clinical experience with the AS04-adjuvanted HBV vaccine among patients with renal insufficiency (including pre-hemodialysis and hemodialysis patients) has demonstrated a favorable safety profile similar to the standard HBV vaccines and has stimulated earlier antibody response and increased antibody titres as compared with 4 double doses of the standard HBV vaccine (Garcon, 2010; Beran, 2008).

The single largest immunization program occurred in the United Kingdom (UK), where AS04-adjuvanted HPV-16/18 vaccine (Cervarix $\left.{ }^{\circledR}\right)$ was the vaccine of choice for mass vaccination of adolescent girls. In a review of safety in the UK following the administration of at least 4 million doses since the start of routine immunization program (September 2008), the Medicines and Healthcare products Regulatory Agency (MHRA, 2010) and Commission on Human Medicines (UK Commission on Human Medicine, 2010) came into conclusion that the benefits of the vaccine continue to outweigh the risks. Similarly, the global monitoring of the available safety data for the AS04-adjuvanted HPV-16/18 vaccine validates its favorable safety profile following the distribution of at least 14 million doses worldwide (Garcon, 2010).

\section{Virosomes}

\section{Mechanism of action}

Virosomes are vaccine platforms that attempts to imitate the structure of a virus. Virosomes are virus-like particles, consisting of reconstituted viral envelopes, lacking the viral genetic material. They are also referred to as Immunopotentiating Reconstituted Influenza Virosomes (IRIV). They are $150 \mathrm{~nm}$ unilamellar vesicular proteoliposomes comprised of influenza H1N1 surface glycoproteins inserted in a mixture of natural and synthetic phospholipids. Virosomes can be generated from different enveloped viruses and are similar to the original virus in terms of morphology and cell entry characteristics. Reconstituted influenza virosomes preserve the receptor-binding and membrane fusion activity of the viral hemagglutinin (HA). Because virosomes do not have the viral RNA, binding and fusion to cells does not result in infection (Wilschut, 2009; Huckriede et al., 2005). Virosomes have been used to enhance the immune response to vaccines against hepatitis A (Epaxal ${ }^{\circledR}$, Berna Biotech) and influenza (Inflexal ${ }^{\circledR} \mathrm{V}$, Berna Biotech (now Crucell) and Invivac, Solvay Pharmaceuticals) (Cusi, 2006).

Clinical studies have shown that intramuscular administration of virosomal influenza vaccines induce hemagglutination-inhibition (HI) titres similar to those stimulated by conventional whole virus or subunit vaccines. Inflexal ${ }^{\circ} \mathrm{V}$ has been proven to have an acceptable immunogenicity and safety profile in healthy adults, elderly and children (Herzog et al., 2002). Inflexal ${ }^{\circledR}$ $\mathrm{V}$ is available under in Italy (Isiflu ${ }^{\circledR} \mathrm{V}$ ), Germany (InfectoVac ${ }^{\circledR}$ Flu), and the United Kingdom (Viroflu ${ }^{\circledR}$ ) (Herzog et al., 2009).

Virosomes are non-toxic, biodegradable, and do not induce antibodies against themselves (Cryz et al., 1996). Virosomes are expected to allow antigen presentation in the context of both MHC I and MHC resulting in both Band T-cell responses (Herzog et al., 2009; Moser et al., 2007; Arkema et al., 2000). Because of their capacity to induce cytokines such as GM-GSF, TNF- $\alpha$, IFN- $\gamma$ and IL-2 in PBMCs and to allow antigen depot, virosomes are capable of improving the immunogenicity of a variety of antigens (Cusi, 2006; Moser et al., 2007). Virosomes interact directly with cells of the immune system, particularly Blymphocytes and dendritic cells. Membrane-associated immunoglobulin receptor molecules on B cells can identify hemagglutinin and neuraminidase spikes projecting from the virosomal membrane, including foreign antigens that may be linked to the surface of the virosomes. The arrangement of the antigens on the virosomal surface is presumed to allow crosslinking of these immunoglobulin receptors on B cells, leading to an exceptionally robust signal and consequent activation (Huckriede et al., 2005; Almeida et al., 1975).

\section{Safety}

Safety and immunogenicity of Inflexal ${ }^{\circledR} \mathrm{V}$ was shown through a randomized trial involving 126 elderly nursing home residents aged 63-102 (Gluck et al., 1994). Another controlled study where 76 elderly subjects were enrolled demonstrated the very good immunogenicity of Inflexal ${ }^{\circledR}$ $\mathrm{V}$ for 2 of the three vaccine strains (Conne et al., 1997). The best response to the vaccine was shown in subjects who had non-protective antibody levels at baseline. A randomized, multi-center study of 533 elderly subjects showed that Inflexal ${ }^{\circledR} \mathrm{V}$ has a better trend than an MF59 adjuvanted vaccine in terms of pain, systemic reactions and additional medication to treat vaccine-related AEs (Zamparo and Little, 2011). Comparable results were found in a controlled study involving 840 subjects aged 60 years or older (Ruf et al., 2004).

Inflexal ${ }^{\circledR} \mathrm{V}$ produced fewer local adverse events, especially where pain and tenderness were concerned $(37 \%)$, in contrast to the comparator vaccine $(51 \%)$ (Herzog et al., 2002). Furthermore, a study in HIVinfected children $(n=23$, mean age $=7.2$ years $)$ showed Inflexal ${ }^{\circ} \mathrm{V}$ to be well-tolerated with no influenza-like illness during 3 months follow-up. Furthermore, no significant changes were observed in the CD4+ count and the viral load. (Herzog et al., 2002; Zuccotti et al., 2002).

A post-marketing study done with 405 children ranging in age from $\geq 6$ months to $\leq 6$ years found Inflexal ${ }^{\circledR}$ $\mathrm{V}$ to be safe, well tolerated and well accepted by parents (Kunzi et al., 2009). Berna Biotech Ltd (now part of Crucell, a subsidiary of Johnson \& Johnson) introduced an influenza virosomal vaccine for intranasal administration (Kunzi et al., 2009) and found that induction of protective immune responses via this route required coadministration of a strong mucosal adjuvant plus 2 consecutive immunizations. This vaccine formulation containing native, non-detoxified, E. coli heat-labile enterotoxin (LT) as mucosal adjuvant, was given marketing approval by Swissmedic in 2001 under the tradename NasalFlu ${ }^{\circledR}$. The vaccine had to be withdrawn soon after 
introduction due to an increased number of cases of Bell's palsy associated with NasalFluß (Mutsch et al., 2004).

A study was performed to compare the immunogenicity and adverse effects of an inactivated hepatitis A vaccine based on virosomes (IRIV- HAV) Epaxal® and a standard vaccine using aluminum as an adjuvant (Al$\mathrm{HAV}$ ). Geometric mean antibody titers recorded at days 0 , 14 and at 12 months were comparable in the two groups (IRIV- HAV and Al-HAV); however, the antibody concentrations recorded with IRIV-HAV at day 28 were lesser $(p<0.0001)$ and at month $13(p=0.02)$. The time to detect protective antibody levels in the blood was similar (Day 28: 98\%, 12 months: 94\%, 13 months: 100\%). Local adverse effects were 17\% (IRIV-HAV) and 66\% (Al-HAV) $(\mathrm{P}<0.0001)$ after the $1^{\text {st }}$ vaccination and $32 \%$ and $42 \%$ respectively following booster $(\mathrm{P}=0.05)$. IRIV-HAV provided similar protection but caused fewer local adverse effects (Holzer et al., 1996).

\section{DISCUSSION}

One of the most important aspects of adjuvant development is safety. Many experimental adjuvants have advanced to clinical trials and some have demonstrated high potency, but most have proven too reactogenic for routine clinical use. Adjuvant safety is critical and can retard, or stop development of an adjuvanted vaccine. The advantages of adding adjuvants into vaccine formulations to improve immunogenicity must be evaluated against the risk that these agents will cause adverse reactions. These adverse reactions often are brought about by the interaction of the adjuvant and the antigen itself, or perhaps because of the specific type of response to a certain antigen the adjuvant generates. Various abnormalities/diseases have been claimed to be linked with the use of adjuvants, for instances, autoimmune diseases, collagen diseases, or even cancer. Extensive epidemiological studies have, however, failed to show an association between adjuvanted vaccines and these theoretical risks. The type of adjuvant will strongly influence the development of antigen-specific T-helper (Th) cell populations, and cell-mediated or antibody profiles (table 2).

Aluminum salts are the reference adjuvants for human vaccines. Various aluminum compounds are used, and aluminum hydroxide is the most widely used. The major mechanisms responsible for the adsorption of alumantigens are electrostatic attraction, hydrophobic forces, and ligand exchange. Alum-containing vaccines have a long experience with hundreds of millions of doses in human vaccines, showing the excellent safety profile: lack of parenteral side effects and relatively benign local side effects at the site of injection. This explains why this class of adjuvants has been a frequent first choice for many vaccines. Alum-containing vaccines can induce local reactions (e.g. redness, pain and hardening of the injection site) in a significant number of recipients, but these are usually mild to moderate and of short duration. Alumcontaining vaccines had been linked to focal histologic lesions which are called macrophagic myofasciitis (MMF). It was first reported in 1998 in France. Five years later, over 200 definite cases had been identified and isolated cases had been recorded in other countries. From an epidemiological perspective, MMF had particularly been observed in France. The increase in the number of cases diagnosed in France in the last few years might be a result of a modification of vaccine administration from the subcutaneous to the intramuscular route, or the use of the hepatitis $B$ vaccine to a naive adult population expected to respond with a more robust local inflammatory response than to booster immunizations. The Vaccine Safety Advisory Committee of the World Health Organization (WHO) reviewed MMF at a meeting of the committee in 1999. The committee found that there was no basis for recommending a change in vaccination practices involving vaccine selection, schedule, delivery practices, or information involving aluminum-containing vaccines. The United States Food and Drug Administration (FDA) also confirmed its support of aluminum salts in vaccines. Alum-containing vaccines are safe.

MF59 was the $1^{\text {st }}$ adjuvant to be approved for human use after aluminum salts. The long period that elapsed between the introduction of aluminum salts and that of MF59 was primarily due to the safety profile that adjuvants must show to gain acceptance for licensure in humans. Unlike many previous candidates, MF59 met all the required criteria for safety. Clinical trials with several MF59-adjuvanted vaccines have been also performed in different age groups (the elderly, younger adults, adolescents, and also newborn infants). There is an integrated analysis from a large safety database, with more than 60 clinical trials and involved 20,447 subjects who received MF59-adjuvanted vaccines. The favorable safety data of MF59-adjuvanted vaccines demonstrated in clinical trials are supported by post-marketing pharmacovigilance. PMS (post-marketing surveillance) during a 9-year period (1997-2006) in which millions of doses of adjuvanted vaccines were administered reported the excellent safety profile of MF59-adjuvanted vaccines.

AS03 is an oil-in-water emulsion adjuvant developed by GSK. It has gained importance in recent years for its use in $\mathrm{H} 1 \mathrm{~N} 1$ pandemic and $\mathrm{H} 5 \mathrm{~N} 1$ pre-pandemic influenza vaccines. AS03 contains a surfactant polysorbate 80 and two biodegradable oils, squalene and $D L-\alpha$ tocopherol, one of the eight isoforms of vitamin E, in phosphate-buffered saline (PBS) as the aqueous carrier. The presence of synthetic $a$-tocopherol as an immunostimulant distinguishes AS03 from MF59, other oilin-water emulsion-based licensed adjuvant. The AS03adjuvanted vaccines were well tolerated with an accepta-

Table 2: Immune Responses Triggered by Adjuvants (O'Hagan and Gregorio, 2009; Vogel and Hem, 2008; Glenn and O'Hagan, 2007).

\begin{tabular}{|c|c|c|c|c|c|c|}
\hline Adjuvants & $\begin{array}{c}\text { Th1 } \\
\text { Response }\end{array}$ & $\begin{array}{c}\text { Th2 } \\
\text { Response }\end{array}$ & $\begin{array}{c}\text { Cross } \\
\text { Priming }\end{array}$ & $\begin{array}{c}\text { B-cell } \\
\text { Response }\end{array}$ & $\begin{array}{l}\text { Mucosal } \\
\text { Response }\end{array}$ & $\begin{array}{l}\text { Persistent T- and } \\
\text { B-cell Response }\end{array}$ \\
\hline $\begin{array}{l}\text { Mineral salts (aluminum salts, } \\
\text { calcium phosphate, AS04) }\end{array}$ & + & ++ & - & ++ & - & + \\
\hline $\begin{array}{l}\text { Emulsions (MF59, QS21, AS02, } \\
\text { IFA, Montanide, ISA51, ISA720) }\end{array}$ & ++ & - & - & +++ & - & + \\
\hline Liposomes & +++ & & + & + & - & + \\
\hline Virosomes (IRIV), ISCOMs & ++ & ++ & ++ & +++ & - & - \\
\hline
\end{tabular}


ble safety profile. There were more than 90 million doses of AS03-adjuvanted H1N1 vaccine administered worldwide in more than 47 countries during the 2009-2010 H1N1 pandemic. Thorough active safety surveillance programs performed by authorities during the pandemic season in 2009-2010 showed a clinically acceptable benefit-risk profile for the AS03-adjuvanted H1N1 vaccines. After the widespread use of the influenza (H1N1) 2009 vaccine, an increase in the number of cases of narcolepsy in children and adolescents have been reported. All of the results provide strengthened evidence that vaccination with Pandemrix ${ }^{\circledR}$ during the pandemic period was linked to an increase in the risk for narcolepsy with cataplexy in children/adolescents 19 years and younger. On the other hand, it should be underlined that both Canada and the United Kingdom did not report any increase in the frequency of narcolepsy after administration of Pandemrix. The genetic susceptibility to narcolepsy in Canada and the United Kingdom is similar to that in the Nordics. This indicates a multifactorial nature of the observed phenomenon. The major difference between AS03 (GSK) and MF59 (Novartis), is the presence of synthetic $\alpha$-tocopherol in AS03. Unlike AS03, MF59adjuvanted vaccines have never been linked to narcolepsy. There is no literature explaining the relationship between the administration/use of vitamin $\mathrm{E}$ and all its isoforms with narcolepsy, suggesting more extensive investigations needed to support the claim that there is a causal relationship between AS03 and narcolepsy.
AS04 combines $50 \mu \mathrm{g}$ of the immunoenhancer MPL (3-O-desacyl-4'-monophosphoryl lipid A) with $500 \mu \mathrm{g}$ of aluminium salt. MPL is a detoxified form of the lipopolysaccharide extracted from the Gram-negative bacterium Salmonella minnesota strain R595. Two AS04-adjuvanted vaccines are licensed for human use: the human papillomavirus 16/18 vaccine, Cervarix ${ }^{\circledR}$ (GlaxoSmithKline) and FENDrix ${ }^{\circledR}$ (GlaxoSmithKline), a hepatitis B virus (HBV) vaccine for hemodialised patients. AS04 represents the first adjuvant licensed for human use in the USA after aluminium salts. A pooled analysis of the safety of the (HPV)-16/18 AS04-adjuvanted cervical cancer vaccine was performed in a cohort of almost 30,000 girls and women aged $\geq 10$ years. Analysis of this large database showed that Cervarix ${ }^{\circledR}$ has a favorable safety profile in women of all ages. Another result from a head-to-head study comparing the AS04-adjuvanted HPV 16/18 vaccine with the quadrivalent HPV vaccine which is adjuvanted with aluminium hydroxide alone, showed the higher local reaction rate in AS04-adjuvanted vaccine group. It is associated with the most likely related to the use of the immunostimulant in AS04.

Virosomes provide the unique opportunity to combine a vaccine antigen and an adjuvant within a single particle. That can be targeted to define cell populations of the immune system. Theoretically, all vaccines can be developed using virosomal approach/technique, but due to the complexity of manufacturing, virosomes have only been used in Influenza (Inflexal® V) and Hepatitis A

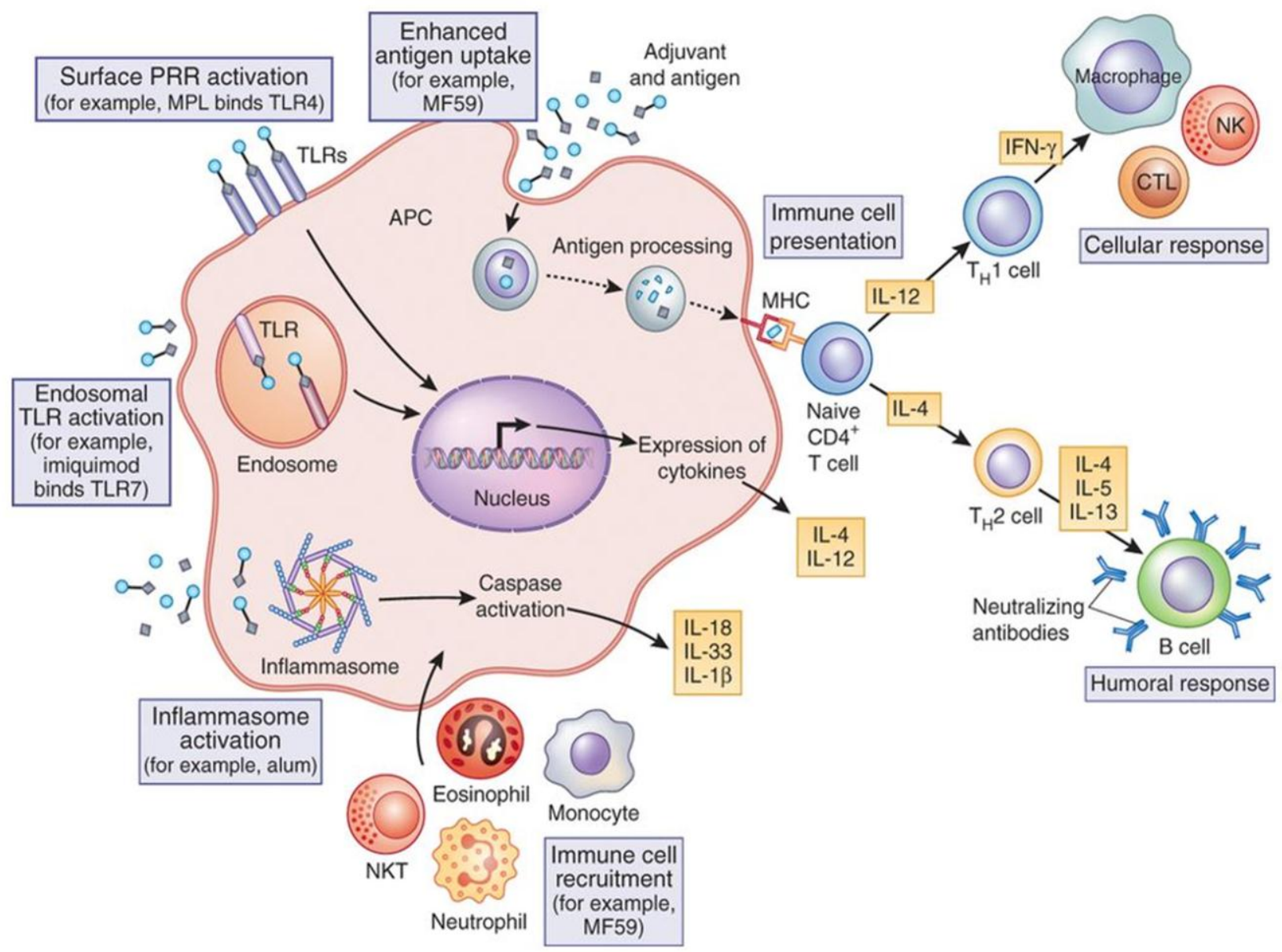

Figure 3: Mechanism of action of the different adjuvants (Reed et al., 2013). 
(Epaxal $\AA$ ) vaccines. Good safety and immunogenicity of Inflexal ${ }^{\circledR}$ were demonstrated in some studies. A multicentre study of 533 elderly subjects showed that Inflexal ${ }^{\circledR}$ $\mathrm{V}$ was better than the comparator using MF59 as an adjuvant in terms of pain, systemic reactions and additional medication to treat vaccine-related AEs. Inflexal ${ }^{\circledR} \mathrm{V}$ was found to possess very good immunogenicity for two of the three vaccine strains. The main advantage was found to be in subjects who possessed non-protective antibody levels at baseline. Inflexal ${ }^{\circledR}$ was also found safe and effective in healthy children and HIVpositive children.

Every adjuvant has a complex and often multifactorial immunological mechanism, usually poorly understood in vivo. Figure 3 shows the proposed mechanism of actions of the different adjuvants. Traditionally, adjuvants have been classified as delivery systems and immunopotentiators. The safety profile of an adjuvant, including the actual and hypothetical risks, is a critical factor that can speed up or impede adjuvant development. To date, there are 5 licensed vaccine adjuvants in US and Europe: Aluminium salts (EU, US), MF59 (EU), AS03 (EU), AS04 (EU, US), and Virosomes (EU). All vaccines that contain these adjuvants have been proven safe, with the exception of the AS03, for which the rare events of narcolepsy have been reported in some countries. Adjuvants have been linked to many theoretical risks, but the studies conducted do not support the causal relationship. The benefits of using adjuvanted-vaccines outweigh the risks. Rational development of classical and novel adjuvants will continue to be one of the most important challenges for the vaccinologist to be able to address persistent unmet medical needs.

\section{CONCLUSION}

Adjuvants are molecules, compounds or macromolecular complexes that enhance the potency and longevity of specific immune response to antigens. Every adjuvant has a complex and often multifactorial immunological mechanism, usually poorly understood in vivo. Traditionally, adjuvants have been classified as delivery systems and immunopotentiators. The safety profile of an adjuvant, including the actual and hypothetical risks, is a critical factor that can speed up or impede adjuvant development. To date, there are 5 licensed vaccine adjuvants in US and Europe: Aluminium salts (EU, US), MF59 (EU), AS03 (EU), AS04 (EU, US), and Virosomes (EU). All vaccines that contain these adjuvants have been proven safe, with the exception of the AS03, for which the rare events of narcolepsy have been reported in some countries. Adjuvants have been linked to many theoretical risks, but the studies conducted do not support the causal relationship. The benefits of using adjuvanted-vaccines outweigh the risks. The increasing understanding in adjuvant sciences is fundamental to the further development of new adjuvants, which may eventually result the development of safer and more effective vaccines.

\section{ACKNOWLEDGEMENT}

The authors would like to thank Prof. Dr. Samsuridjal Djauzi, Sp.PD-KAI, Novartis Vaccines Academy, Professor Emmanuel Montomoli, Prof Dr. Sue Ann CostaClemens, Prof Dr. Ralf Clemens and Dr. Rino Rappuoli.

\section{REFERENCES}

Almeida JD, Brand CM, Edwards DC, Heath TD. (1975) Formation of virosomes from influenza subunits and liposomes. Lancet, Vol. 2, pp. 899-901. [DOI]

Alving CR. (2009) Vaccine adjuvants. Vaccines for Biodefense and Emerging and Neglected

Arkema A, Huckriede A, Schoen P, Wilschut J, Daemen T. (2000) Induction of cytotoxic T lymphocyte activity by fusion-active peptide-containing virosomes. Vaccine, Vol. 18, pp. 1327-1333. [DOI]

Banzhoff A, Haertel S, Praus M. (2011) Passive surveillance of adverse events of an MF59-adjuvanted H1N1v vaccine during the pandemic mass vaccinations. Human Vaccines, Vol. 7, pp. 539-548. [DOI]

Banzhoff A, Nacci P, Podda A. (2003) A new MF59-adjuvanted influenza vaccine enhances the immune response in the elderly with chronic diseases: results from an immunogenicity meta-analysis. Gerontology, Vol. 49, pp. 177-84. [DOI]

Baylor NW, Egan W, Richman P. (2002) Aluminum salts in vaccine-US perspective. Vaccine, Vol. 20, p. S18 - S23. [DOI]

Beran J. (2008) Safety and immunogenicity of a new hepatitis B vaccine for the protection of patients with renal insufficiency including prehaemodialysis and haemodialysis. Expert Opin Biol Ther, Vol. 8, pp. 235-247. [DOI]

Brennan FR, Dougan G. (2005) Non-clinical safety evaluation of novel vaccines and adjuvants. Vaccine, Vol. 23. pp. 362 -368. [DOI]

Brigelius-Flohé R, Traber MG. (1999) Vitamin E function and metabolism. FASEB J, Vol. 13, pp. 1145-1155. PMid:10385606

Burton GW, Traber MG, Acuff RV, Walters DN, Kayden H, Hughes L, Ingold KU. (1998) Human plasma and tissue alpha-tocopherol concentrations in response to supplementation with deuterated natural and synthetic vitamin E. Am. J. Clin. Nutr., Vol. 67, pp. 669-684. PMid:9537614

Casella CR, Mitchell TC. (2008) Putting endotoxin to work for us: monophosphoryl lipid A as a safe and effective vaccine adjuvant. Cell Mol Life Sci, Vol. 65, pp. 3231-3240. [DOI]

Conne P, Gauthey L, Vernet P, Althaus B, Que JU, Finkel B, Glück R, Cryz SJ Jr. (1997) Immunogenicity of trivalent subunit versus virosomeformulated influenza vaccines in geriatric patients. Vaccine, Vol. 15, pp 1675-1679. [DOI]

Cryz SJ, Que JU, Gluck R. (1996) A virosome vaccine antigen delivery system does not stimulate an antiphospholipid antibody response in humans. Vaccine, Vol. 14, pp. 1381-1383. [DOI]

Cusi MG. (2006) Review: applications of influenza virosomes as a delivery system. Human Vaccines, Vol. 2, pp. 1-7. [DOI]

De Donato S, Granoff D,Minutello M, Lecchi G, Faccini M, Agnello M, Senatore F,

Demicheli V, Rivetti A, DiPietrantonj C, Clements CJ, Jefferson T. (2003) Hepatitis B vaccination and multiple sclerosis: evidence from a systematic review. J Viral Hepat, Vol. 10, pp. 343-344. [DOI]

Descamps D, Hardt K, Spiessens B, Izurieta P, Verstraeten T, Breuer T, et al. (2009) Safety of human papillomavirus (HPV)-16/18 AS04adjuvanted vaccine for cervical cancer prevention: a pooled analysis of 11 clinical trials. Hum Vaccin, Vol. 5, pp. 332-340. [DOI]

Didierlaurent AM, Morel S, Lockman L, Giannini SL, Bisteau M, Carlsen $\mathrm{H}$, et al. (2009) AS04, an aluminum salt- and TLR4 agonist-based adjuvant system, induces a transient localized innate immune response leading to enhanced adaptive immunity. J Immunol, Vol. 183, pp. 186197. [DOI]

Diseases: Elsevier, 2009. pp 117-125. [DOI]

Dupuis M, McDonald DM, Ott G. (2000) Distribution of adjuvant MF59 and antigen gD2 after intramuscular injection in mice. Vaccine, Vol. 18 pp. 434-39. [DOI]

Dupuis M, Murphy TJ, Higgins D, Ugozzoli M, van Nest G, Ott G, McDonald DM. (1998) Dendritic cells internalize vaccine adjuvant after intramuscular injection. Cell Immunol, Vol. 186, pp. 18-27. [DOI]

Edelman R. (2002) The development and use of vaccine adjuvants. Molecular Biotechnology, Vol. 21. pp. 129-148. [DOI]

Einstein MH, Baron M, Levin MJ, Chatterjee A, Edwards RP, Zepp F, et al. (2009) Comparison of the immunogenicity and safety of Cervarix and Gardasil human papillomavirus (HPV) cervical cancer vaccines in healthy women aged 18-45 years. Hum Vaccines, Vol. 5, pp. 705-719. [DOI]

Eisenbarth SC, Colegio OR, O'Connor W, Sutterwala FS, Flavell RA. (2008) Crucial role for the Nalp3 inflammasome in the immunostimulatory properties of aluminium adjuvants. Nature, 2008, Vol. 453, pp. 11221126. [DOI] 
EMA. (2005) Guideline on adjuvants in vaccines for human use. s.l. : Committee for Medicinal Products for Human Use 2005. EMEA/CHMP/VEG/134716/2004. Available at: [Link]

Frey S, Poland G, Percell S, Podda A. (2003) Comparison of the safety tolerability and immunogenicity of a MF59-adjuvanted influenza vaccine and a non nonadjuvanted. Vaccine, Vol. 21, pp. 4234-37. [DOI

Garcon N. (2010) Preclinical development of AS04. Methods Mol Biol. Vol 626, pp. 15-27. [DOI]

Garçon, Vaughn DW, Didierlaurent AM. (2012) Development and evaluation of AS03, an Adjuvant System containing a-tocopherol and squalene in an oil-in-water emulsion. Expert Rev. Vaccines, Vol. 11, pp 349-366. [DOI]

Gasparini R, Pozzi T, Montomoli E, Fragapane E, Senatore F, Minutello M, Podda A. (2001) Increased immunogenicity of the MF59-adjuvanted influenza vaccine compared to a conventional subunit vaccine in elderly subjects. Eur J Epidemiol, Vol. 17, pp. 135-40. [DOI]

Gherardi RK, Authier FJ. (2003) Aluminium inclusion macrophagic myofasciitis: a recently identified condition. Immunol Allergy Clin $\mathrm{N}$ Am, Vol. 23, p. 699-712. [DOI]

Gherardi RK, Coquet M, Cherin P, Authier FJ, Laforet P, Belec L, et al. (1998). Macrophagic myofasciitis: an emerging entity. The Lancet, Vol 352, p. 347-52. [DOI]

Gherardi RK, Coquet M, Cherin P, Belec L, Moretto P, Dreyfus PA, et al. (2001) Macrophagic myofasciitis lesions assess long-term persistence of vaccine-derived aluminium hydroxide in muscle. Brain, Vol. 124, pp. 1821-1831. [DOI]

Gherardi RK. (2003) Lessons from macrophagic myofasciitis: towards definition of a vaccine adjuvant-related syndrome. Rev Neurol, Vol. 159, p. $162-64$. [DOI]

Glenn GM, O'Hagan DT. (2007) Adjuvants: progress, regress and pandemic preparedness. Expert Rev Vaccines, Vol. 6. pp. 651-652. [DOI]

Glück R, Mischler R, Finkel B, Que JU, Scarpa B, Cryz Jr SJ. (1994) Immunogenicity of new virosome influenza vaccine in elderly people. Lancet, Vol. 344, pp. 160-163. [DOI]

Gupta RK, Rost BE, Relyveld E, Siber GR. (1995) Adjuvant properties of aluminum and calcium compounds. Newman MJ, ed Powell MF. Vaccine Design: the Subunit and Adjuvant Approach. New York : Plenum Press, pp. 237-238. [DOI]

Gupta RK. (1998) Aluminum compounds as vaccine adjuvants. Adv Drug Deliv. Rev, 1998, Vol. 32, p. 155-72. [DOI]

Halsey NA. (2003) Vaccine safety: real and perceived issues. The vaccine book. USA : Elsevier science. pp. 371-389. [DOI]

Heikkinen T, Young J, van Beek E, Franke H, Verstraeten T, Weil JG, Della Cioppa G. (2012) Safety of MF59-adjuvanted A/H1N1 influenza vaccine in pregnancy: a comparative cohort study. Am J Obstet Gynecol. Vol 3:177.e1-8. [DOI]

Hem SL, Klepak PB, Lindblad EB. (2006) Aluminum hydroxide adjuvant. Sheskey PJ, Owen SC, ed Rowe RC. Handbook of Pharmaceutical Excipients. London : Pharmaceutical Press, pp. 36-40. [DOI]

Hem SL. (2002) Elimination of aluminum adjuvants. Vaccine, Vol 20 Supp 3, p. 40-43. [DOI]

Herbert WJ. (1966) Antigenicity of soluble protein in the presence of high levels of antibody: a possible mode of action of the antigen adjuvants. Nature, Vol. 210, pp. 747-748. [DOI]

Herzog C, Hartmann K, Kunzi V, Kursteiner O, Mischler R, Lazar H, Gluck R. (2009) Review: eleven years of Inflexal® V - a virosomal adjuvanted influenza vaccine. Vaccine, Vol. 27, pp. 4381-4387. [DOI]

Herzog C, Metcalfe IC, Schaad UB. (2002) Virosomes influenza vaccine in children.. Vaccine, Vol. 20, pp. 24-28. [DOI]

Holzer BR, Hatz C, Sissolak DS, Gluck R, Althaus B, Egger M. (1996) Immunogenicity and adverse effects of inactivated virosome versus alum-adsorbed hepatitis A vaccine: a randomized controlled trial. Vaccine, Vol. 14, pp. 982-986. [DOI]

Huckriede A, Bungener L, Stegmann T, Daemen T, Medema J, Palache AM, Wilschut J. (2005) Review: the virosome concept for influenza vaccines. Vacine, Vol. 23, pp. 26-38. [DOI]

Jefferson T, Rudin M, DiPietrantonj M. (2003) Systematic review of the effects of pertussis vaccines in children. Vaccine, Vol. 21, pp. 2012-23. [DOI]

Jefferson T, Rudin M, Pietrantonj CD. (2004) Adverse events after immunisation with aluminium-containing DTP vaccines: systematic review of the evidence. Lancet Infect Dis, Vol. 4, pp. 84-90. [DOI]

Julkunen I and Partinen M. (2014). Neuroimmunology: Disease mechanisms in narcolepsy remain elusive. Nature Reviews Neurology Volume: 10, pp. Pages: 616-617 [DOI]
Keith LS, Jones DE, Chou CH. (2002) Aluminum toxicokinetics regarding infant diet and vaccinations. Vaccine, Vol. 20, pp. 13-17. [DOI]

Kenney RT, Cross AS. (2010) Adjuvants for the future. Levine MM. New generation vaccines 4 th ed. New York : Informa Healthcare USA, pp 250-262.

Kool M, Soullie T, van Nimwegen M, Willart MAM, Muskens F, Jung S, et al. (2008) Alum adjuvant boosts adaptive immunity by inducing uric acid and activating inflammatory dendritic cells. J. Exp. Med, 2008, Vol 205, pp. 869-882. [DOI]

Künzi V, DornseiffM, Horwath J, Hartmann K. (2009) Safe vaccination of children with a virosomal adjuvanted influenza vaccine. Vaccine, Vol 27, pp. 1261-1265. [DOI]

Langley JM, Risi G, Caldwell M, Gilderman L, Berwald B, Fogarty C, Poling T, Riff D, Baron M, Frenette L, Sheldon E, Collins H, Shepard M, Dionne M, Brune D, Ferguson L, Vaughn D, Li P, Fries L. (2011) Dosesparing H5N1 A/Indonesia/05/2005 pre-pandemic infl uenza vaccine in adults and elderly adults: a Phase III, placebo controlled randomized study. J. Infect. Dis, Vol. 203, pp. 1729-1738. [DOI]

Li H, Nookala S, Re F. (2007) Aluminum hydroxide adjuvants activate caspase-1 and induce IL-1 beta and IL-18 release. J. Immunol, Vol. 178, pp. 5271-5276. [DOI]

Martin JT. (1997) Development of an adjuvant to enhance the immune response to influenza vaccine in the elderly. Biologicals, Vol. 25, pp. 209-213. [DOI]

McKeage K, Romanowski B. (2011) AS04-adjuvanted human papillomavirus (HPV) types 16 and 18 vaccine (Cervarix): A review of its use in the prevention of premalignant cervical lesions and cervical cancer causally related to certain oncogenic HPV types. Drugs, Vol. 71, pp. 465-488. [DOI].

McPhillips H, Marcuse EK. (2001) Vaccine safety. Curr Probl Pediatr, Vol 31. pp 91-121. http://dx.doi.org/10.1016/s1538-5442(01)70025-9

Medicines and Healthcare Products Regulatory Agency. (2010) MHRA Public Assessment Report, October 2010: Cervarix (HPV vaccine): Update on UK safety covering the first two years of the HPV immunisation programme. [Accessed 21 March 2015]. Available at: [Link]

Minutello M, Senatore F, Cecchinelli G, Bianchi M, Andreani T, Podda A Crovari P. (1999) Safety and immunogenicity of an inactivated subunit influenza virus vaccine combined with MF59 adjuvant emulsion in elderly subjects, immunized for three consecutive influenza seasons. Vaccine, Vol. 17, pp. 99-104. [DOI]

Morefield GL, Sokolovska A, Jiang D, HogenEsch H, Robinson JP, Hem SL. (2005) Role of aluminum containing adjuvants in antigen internalization by dendritic cells in vitro. Vaccine, p. Vol. 13. 1588-1595. PMID: 15694511

Moser C, AmackerM, Kammer AR, Rasi S, Westerfeld N, Zurbriggen R. (2007) Influenza virosomes as a combined vaccine carrier and adjuvant system for prophylactic and therapeutic immunizations. Expert Review Vaccines, Vol. 6, pp. 711-721. [DOI]

Mutsch M, Zhou W, Rhodes P, Bopp M, Chen RT, Linder T, Spyr C, Steffen R. (2004) Use of the inactivated intranasal influenza vaccine and the risk of Bell's palsy in Switzerland. New Engl J Med, Vol. 350, pp. 896890. [DOI]

Naschitz JE, Jochanan HB, Misslevich I, Yeshurun D, Rosner I. (1996) The fasciitis-panniculitis syndromes: clinical and pathological features. Medicine, Vol. 75, p. 6-16. [DOI]

National Institute for Health and Welfare of Finland. (2011) National Narcolepsy Task Force 31 January 2011. [Accessed 21 March 2015] Available at: [Link]

Nohynek H, Jokinen J, Partinen M, Vaarala O, Kirjavainen T, Sundman J, Himanen SL, Hublin C, Julkunen I, Olsén P, Saarenpää-Heikkilä O, Kilpi T. (2012) AS03 adjuvanted AH1N1 vaccine associated with an abrupt increase in the incidence of childhood narcolepsy in Finland PLoS ONE, Vol. 7, pp. 1-9. [DOI]

O'Hagan DT, Gregorio ED. (2009) The path to a successful vaccine adjuvant. Drug Discovery Today, 2009, Vol. 14. pp. 541-551. [DOI]

O'Hagan DT, Rappuoli R, De Gregorio E, Tsai T, Del Giudice G. (2011) MF59 adjuvant: the best insurance against influenza strain diversity. Expert Review of Vaccines, Vol. 10, pp. 447-462. [DOI]

Offit PA, Davis RL, Gust D. (2008) Vaccine safety. In: Vaccines (5th Edition). Plotkin SA, Orenstien WA, Offit PA (Eds). Saunders Elsevier, PA, USA, 1629-1650.

O'Hagan DT, Rappuoli R. (2004) The safety of vaccines. 19: Drug Discovery Today, 2004, Vol. 9. pp $846-854$. [DOI]

O'Hagan DT. (2007) New Generation Vaccine Adjuvants. Encyclopedia of life and sciences, John Wiley \& Sons, Ltd. [DOI]

Pellegrini M, Nicolay U, Lindert K, Groth N, Della Cioppa G. (2009) MF59adjuvanted versus non-adjuvanted influenza vaccines: integrated 
analysis from a large safety database. Vaccine, Vol. 27, pp. 6959-6965. [DOI]

Podda A, Del Giudice G, O'Hagan D. (2005) MF59: a safe and potent adjuvant for human use. Immunopotent Mod Vacc, pp. 149-59.

Podda, A. (2001) The adjuvanted influenza vaccines with novel adjuvants: experience with the MF59-adjuvanted vaccine. Vaccine, Vol. 19, pp. 2673-80. [DOI]

Qureshi N, Takayama K, Ribi E. (1982) Purification and structural determination of nontoxic lipid A obtained from the lipopolysaccharide of Salmonella typhimurium. J Biol Chem, Vol. 257, pp. 11808-11815. PMid:6749846

Reed S, Orr MT, Fox CB. (2013) Key roles of adjuvants in modern vaccines. Nature Medicine, Vol 19, pp. 1597-1608. http://dx.doi.org/10.1038/nm.3409

Relyveld EH, Bizzini B, Gupta KR. (1998) Rational approaches to reduce adverse reactions in man to vaccines containing tetanus and diphtheria toxoids. Vaccines, Vol. 16, p. 1016-23. [DOI]

Rimaniol AC, Gras G, Verdier F, Capel F, Grigoriev VB, Porcheray F, et al. (2004) Aluminum hydroxide adjuvant induces macrophage differentiation towards a specialized antigen-presenting cell type. Vaccine, 2004, Vol. 22, pp. 3127-3135. [DOI]

Ruf BR, Colberg K, FrickM, Preusche A. (2004) Open, randomized study to compare the immunogenicity and reactogenicity of an influenza split vaccine with an MF59-adjuvanted subunit vaccine and a virosomebased subunit vaccine in elderly. Infection, Vol. 32, pp. 191-198. [DOI]

Rümke HC, Bayas J-M, de Juanes J-R, Caso C, Richardus JH, Campins M, Rombo L, Duval X, Romanenko V, Schwarz TF, Fassakhov R, AbadSantos F, von Sonnenburg F, Dramé M, Sänger R, Ballou WR. (2008) Safety and reactogenicity profile of an adjuvanted H5N1 pandemic candidate vaccine in adults within a Phase III safety trial. Vaccine, Vol 26, pp. 2378-2388. [DOI]

Sahly HE. (2010) MF59 as a vaccine adjuvant: a review of safety and immunogenicity. Expert Rev Vaccines, Vol. 9, pp. 1135-41. [DOI]

Schaad UB, Bühlmann U, Burger R, Ruedeberg A, Wilder-Smith A, Rutishauser M, Sennhauser F, Herzog C, Zellmeyer M, Glück R. (2000) Comparison of immunogenicity and safety of a virosome influenza vaccine with those of a subunit influenza vaccine in pediatric patients with cystic fibrosis. Antimicrob Agent Chemother, Vol. 44, pp. 1163 1167. [DOI]

Schijns V, Lavelle EC. (2011) Trends in vaccine adjuvants. Expert Rev. Vaccines, Vol. 10. pp. 539-550. [DOI]

Schultze V, D'agosto V, Wack A, Novicki D, Zorn J, Hennig R. (2008) Review: safety of MF59 adjuvant. Vaccine, Vol. 26, pp. 3209-3222. [DOI]

Sesardic D, Dobbelaer R. (2004) European union regulatory developments for new vaccine adjuvants and delivery systems. Vaccine, Vol. 22. pp. 2452 - 2456. [DOI]

Sesardic D, Rijpkema S, Patel BP (2007). New adjuvants: EU regulatory developments. Expert Rev. Vaccines, Vol. 6. pp. 849-861. [DOI]
Seubert A, Monaci E, Pizza M, O'Hagan DT, Wack A. (2008) The adjuvants aluminum hydroxide and MF59 induce monocyte and granulocytechemoattractants and enhance monocyte differentiation toward dendritic cells. J Immunol, Vol. 180, pp. 5402-5412. [DOI]

Singh M, Ugozzol M, Kazzaz J, Chesko J, Soenawan E, Donatella M. (2006) Evaluation of alternative delivery systems for antigens and their comparison to alum. Vaccine, Vol. 2410, pp. 1680-86. [DOI]

Swedish Medical Products Agency. (2011) A registry based comparative cohort study in four Swedish counties of the risk for narcolepsy after vaccination with Pandemrix - A first and preliminary report. 2011. [Accessed 21 March 2015] Available at: [Link]

Tsai TF, Cruciti A, Nacci P, Nicolay U, Della Cioppa G, Ferguson J, Clemens R. (2011) Explorations of clinical trials and pharmacovigilance databases of MF59-adjuvanted infl uenza vaccines for associated cases of narcolepsy. Scand J Infect Dis, Vol. 43, pp. 702-706. [DOI]

UK Commission on Human Medicine. (2010) Human papilloma virus (HPV) vaccine: 2-year safety review. In the summary report based on the minutes of the meeting of the pharmacovigilance expert advisory group held on 15th September 2010. 2010. [Accessed 21 March 2015] Available at: [Link]

Ulanova M, Tarkowski A, Hahn-Zoric M, Hanson LA. (2001) The common vaccine adjuvant aluminum hydroxide upregulates accessory properties of human monocytes via an interleukin-4 dependent mechanism. Infect. Immun, Vol. 69, pp. 1151-1159. [DOI]

Vallabhapurapu S, Karin M. (2009) Regulation and function of NF-kB transcription factors in the immune system. Annu Rev Immuno, Vol. 27, pp. 693-733. [DOI]

Verdier F. (2002) Non-clinical vaccine safety assesment. Toxicology, Vol. 174. pp 37-43. [DOI]

Vesikari T, Groth N, Karvonen A, Borkowski A, Pellegrini M. (2009) MF59adjuvanted influenza vaccine (Fluad) in children: safety and immunogenicity following a second year seasonal vaccination. Vaccine, Vol. 27, pp. 6291-6295. [DOI]

Wilschut J. (2009) Influenza vaccines: the virosome concept. Elsevier, Vol. 122, pp. 118-21. [DOI]

World Health Organization. (1999) Weekly Epidemiological Record on macrophagic myofasciitis and aluminium-containing vaccines. pp. 33748. [Accessed 21 March 2015]. Available at: http://www.who.int/vaccine safety/committee/reports/october 1999/en

World Health Organization. WHO Global Advisory Committee on Vaccine Safety (GACVS). [Online] 21 April 2011. [Accessed 29 April 2015]. Available at: [Link]

Zamparo E, Little D. (2011) Immunogenicity and effectiveness of virosomal adjuvanted vaccines against influenza: a brief review of their utility in the elderly population. Journ Prev Med Hyg Vol 52, pp. 116-119. PMid:22010538

Zuccotti GV, Cucchi C, Sala D, Giovannini M. (2002) Immunogenicity and safety of a virosomal influenza vaccine in HIV-infected children. Acta Pediatr, Vol. 91, pp. 486-487. [DOI] 